\title{
Supported hydrotalcites as highly active solid base catalysts
}

\author{
Ferry Winter, A. Jos van Dillen and Krijn P. de Jong* \\ Received (in Cambridge, UK) 4th May 2005, Accepted 15th June 2005 \\ First published as an Advance Article on the web 8th July 2005 \\ DOI: 10.1039/b506173c
}

$\mathrm{Mg}-\mathrm{Al}$ hydrotalcite platelets with a lateral size of $20 \mathrm{~nm}$ were deposited on carbon nanofibers and the resulting supported catalyst exhibited a specific activity in the condensation of acetone four times that of unsupported hydrotalcites due to the higher number of active edge sites.

In the search for more environmentally benign catalysts for replacing homogeneous catalysts, activated hydrotalcites are of great interest as solid base catalysts in several reactions, such as Knoevenagel condensations, Michael additions, Claisen-Schmidt and aldol condensations. ${ }^{1-6}$ Activated $\mathrm{Mg}-\mathrm{Al}$ hydrotalcites (HT) are capable of catalyzing liquid-phase aldol condensation reactions at low temperatures with appreciable activity and high selectivity. ${ }^{5,7-10}$

HT, $\mathrm{Mg}_{6} \mathrm{Al}_{2}(\mathrm{OH})_{16} \mathrm{CO}_{3} \cdot 4 \mathrm{H}_{2} \mathrm{O}$, is an anionic clay with a structure similar to that of brucite $\left(\mathrm{Mg}(\mathrm{OH})_{2}\right)$. Compared to the latter structure, in $\mathrm{HT}$ part of the $\mathrm{Mg}$ cations is replaced with $\mathrm{Al}^{3+}$ and the resulting positive charge is compensated by anions, typically carbonate, in the interlayer between the brucite-like sheets. ${ }^{11}$ The generally applied method for activation of HT involves a heat treatment wherein the layered structure is destroyed to form a mixed oxide. In a next step the material is rehydrated to restore the originial HT structure to a large extent and with the exclusion of other anions and $\mathrm{CO}_{2}$, Brønsted base sites $\left(\mathrm{OH}^{-}\right)$are incorporated in the interlayer. . $^{2,5,9,12}$

Recently, it was found by several authors that the actual active sites participating in catalysis are situated at the edges of the platelets. $^{9,13-15}$ Several attempts have been made to increase the number of edge sites of the HT platelets, ${ }^{9,14,15}$ however, the exposed edge area is limited by the lateral size of HT crystallites. The size can be varied by using different crystallization temperatures, but the lower limit in the lateral dimension that could be obtained up to now is $60-70 \mathrm{~nm} .^{9,14,16}$ Further studies to synthesize smaller crystallites is therefore beneficial to obtain more efficient catalysts. Furthermore, to utilize HT as a catalyst in slurry-phase processes, it is advantageous to have mechanically strong HT bodies of 20 $100 \mu \mathrm{m}$ to facilitate fast removal of the catalyst by filtration. However, HT has low mechanical strength and it is difficult to shape the materials. Skeins of carbon nanofibers as support could provide the mechanical properties desired for the catalyst. ${ }^{17}$

In this study, hydrotalcites platelets are deposited on carbon nanofibers as support. The materials are investigated as solid base catalysts in aldol-type condensation reactions.

Carbon nanofibers (CNF) were used as support after removal of the $\mathrm{Ni} / \mathrm{SiO}_{2}$ growth catalyst by treatment in $\mathrm{KOH}$ and

Department of Inorganic Chemistry and Catalysis, Debye Institute, Utrecht University, Sorbonnelaan 16, 3584 CA, Utrecht,

The Netherlands. E-mail: k.p.dejong@chem.uu.nl; Fax: +31 30251 1027; Tel: +31302536762 subsequently in concentrated $\mathrm{HNO}_{3}$, followed by thorough washing. Hydrotalcite $(\mathrm{Mg} / \mathrm{Al}=2)$ was precipitated in the pores of carbon nanofibers bodies by subsequent incipient wetness impregnation of the constituents as described belowt. For comparison reasons, an unsupported HT was synthesized at $333 \mathrm{~K}$ as described elsewhere. ${ }^{9,10,18}$ Activation of the as synthesized supported HT (HT/CNF-as) and the unsupported HT involved a heat treatment up to $773 \mathrm{~K}$ and subsequent rehydration (further denoted as HT/CNF-act and HT-act, respectively).

In Table 1 some physico-chemical properties of the various samples are given. The BET surface area and the pore volume of the HT/CNF samples are significantly lower than observed with $\mathrm{CNF}$, which indicates a partial filling of the pores with HT. The material still has a well accessible pore system as suggested by the pore diameter (19 nm, data not shown) and the absence of micropores. A loading of $11 \mathrm{wt} \%$ HT was obtained as determined from thermogravimetric analysis.

The XRD patterns of the HT/CNF samples at different synthesis stages as well as the unsupported HT are given in Fig. 1. The diffraction lines resulting from HT and those of the carbon support are indicated. The most intense line of HT can be found at 13.2 degrees $2 \theta$ (003), but also other characteristic peaks in the HT/CNF patterns can be clearly distinguished. It is important to stress that the peaks in HT/CNF-as are broader than

Table 1 Results from nitrogen physisorption and TGA

\begin{tabular}{llll}
\hline & $S_{\text {BET }}\left(\mathrm{m}^{2} \cdot \mathrm{g}^{-1}\right)^{a}$ & $V_{\text {meso }}\left(\mathrm{cm}^{3} \cdot \mathrm{g}^{-1}\right)$ & HT loading $(\%)$ \\
\hline CNF & 89 & 0.47 & 0 \\
HT/CNF-as & 72 & 0.35 & 11 \\
HT/CNF-act & 77 & 0.37 & 11 \\
\multicolumn{2}{l}{ No micropores observed ( $t$-plot $).$} & \\
\hline
\end{tabular}

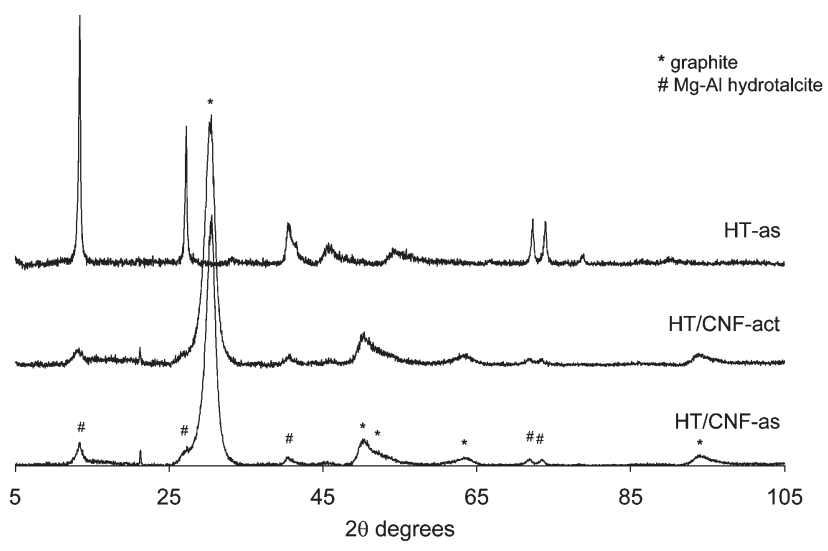

Fig. 1 XRD patterns of HT/CNF-as, HT/CNF-act and HT-as. 


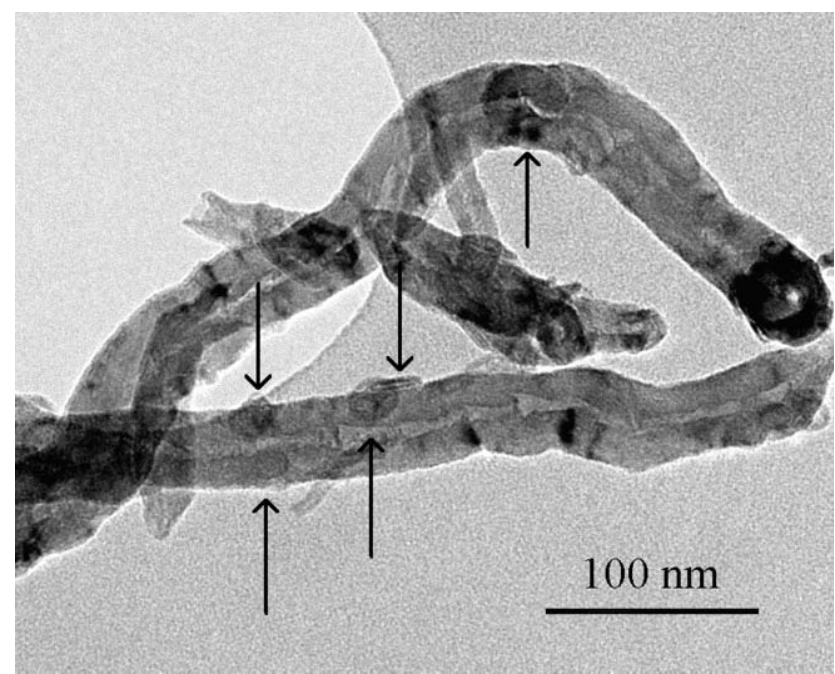

Fig. 2 TEM micrograph of HT/CNF-as.

those observed with the unsupported HT. This peak broadening is even more pronounced after activation of the sample (HT/CNFact). The peak broadening implies that the HT crystallites in the HT/CNF samples are smaller than those of the unsupported HT, while prepared at similar crystallization temperatures.

A representative TEM micrograph of HT/CNF-as is given in Fig. 2. Very small hexagonal platelets were found on the carbon nanofibers as indicated with arrows. The size of these platelets was found to be about $20 \mathrm{~nm}$ in the lateral direction, with stacks of about 5-6 nm. Performing EDX analysis during investigation with TEM (spot size 3-4 nm) on these platelet-like structures revealed $\mathrm{Mg}$ and $\mathrm{Al}$, whereas no $\mathrm{Mg}$ and $\mathrm{Al}$ were detected on seemingly bare fibers. Furthermore, no HT platelets next to the support were detected with TEM analysis, which demonstrates that HT is solely supported on the carbon nanofibers. The platelet size of the unsupported HT was found to be much larger, $\sim 60-70 \mathrm{~nm}$.

The catalytic properties of the various materials were investigated in the self-condensation of acetone to diacetone alcohol (DAA) at $273 \mathrm{~K}$ and the condensation of citral and acetone to pseudoionone at $333 \mathrm{~K}$. The as synthesized materials did not exhibit any catalytic activity in these reactions. The initial activity of the activated samples is given in Table 2. HT-act exhibited an activity comparable to values reported in the literature. ${ }^{9,14}$ The specific activity on HT-weight basis of HT/CNF-act in the selfcondensation of acetone is extremely high, about fourfold that of HT-act. The total number of accessible active sites of the activated materials was determined with volumetric $\mathrm{CO}_{2}$ adsorption measurements. A relatively high number of active sites of HT/ CNF-act was found compared to HT-act, which is due to the small crystallites found with XRD and TEM. The number of accessible active sites is determined by the lateral dimensions of the

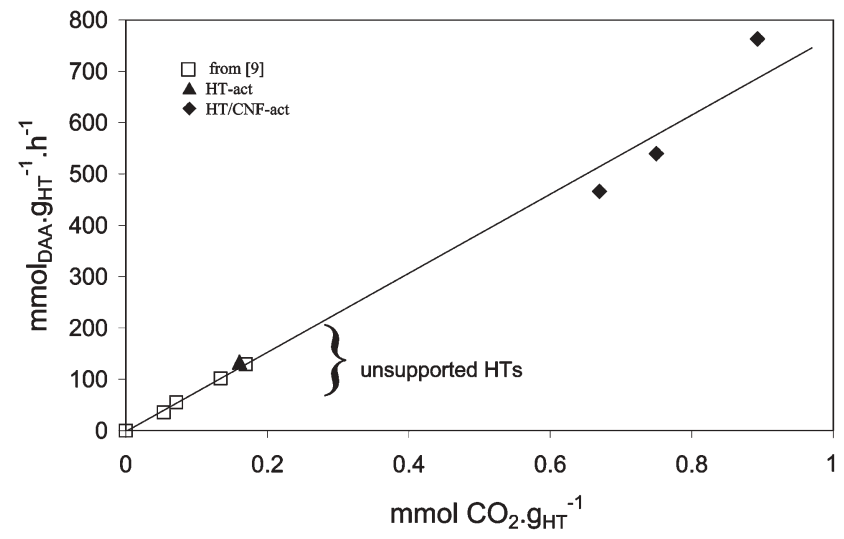

Fig. 3 Initial activity in the condensation of acetone at $273 \mathrm{~K}$ vs. $\mathrm{CO}_{2}$ adsorption of unsupported HTs and HT/CNF-act samples.

platelets, as the active sites are situated at the edges of the platelets. The turnover frequencies (TOF) as given in Table 2 are similar. In Fig. 3 the initial activity of HT-act and various HT/CNF-act samples versus the number of accessible active sites is given as well as the correlation reported earlier by Roelofs et al. with activated HTs with different platelet sizes. ${ }^{9}$ Not only does HT-act fit nicely within this correlation, it clearly demonstrates that this correlation is viable over a large range since extrapolation of this correlation to the HT/CNF-act samples is very good. These results further support the model that the actual active sites are situated at the edges of the platelets, ${ }^{9,14,15}$ in contrast to results of studies on structure-activity relationships on activated hydrotalcites wherein a correlation between activity and surface area was proposed. ${ }^{15,19}$ Note the large improvement in efficiency of the HT/CNF-act samples compared to the unsupported HT-act and to values reported in recent studies on activated hydrotalcites in condensation reactions. ${ }^{8,9,14,15}$ The catalysts showed high selectivity to pseudoionone (above 97\%) and diacetone alcohol (higher than $99 \%$ ) and were active over several hours of reaction. The used catalyst could be easily reactivated with similar catalytic properties by a repeated heat treatment and rehydration.

In conclusion, HT can be deposited on carbon nanofibers. Furthermore, our results show that small HT platelets can be synthesized with sizes not reported earlier. Due to the well accessible pore system of the carbon nanofiber bodies, a high number of accessible $\mathrm{OH}^{-}$can be obtained, which is important to improve the activity, hence the efficiency of the catalyst. The linear correlation between the number of accessible active sites and the initial activity in the self-condensation of acetone is extended over a large range and further supports the model that the sites participating in catalysis are situated at the edges of the platelets.

We would like to thank J. D. Meeldijk, V. Koot, A. Broersma and A. J. M. Mens for their technical assistance, Prof. J. W. Geus for TEM analysis and useful discussions. The Netherlands

Table 2 Catalytic properties and the number of active sites as determined with $\mathrm{CO}_{2}$ adsorption

\begin{tabular}{|c|c|c|c|c|}
\hline & $\begin{array}{l}\mathrm{CO}_{2} \text { adsorption } \\
\left(\mu \mathrm{mol} \cdot \mathrm{g}_{\mathrm{HT}}{ }^{-1}\right)\end{array}$ & $\begin{array}{l}\text { Initial rate }^{a} \\
\left(\mathrm{mmol}_{\mathrm{DAA}} \cdot \mathrm{g}_{\mathrm{HT}}{ }^{-1} \cdot \mathrm{h}^{-1}\right)\end{array}$ & $\begin{array}{l}\mathrm{TOF}^{b} \\
\left(\mathrm{~s}^{-1}\right)\end{array}$ & $\begin{array}{l}\text { Initial rate } \\
\left(\mathrm{mmol}_{\text {citral }} \cdot \mathrm{g}_{\mathrm{HT}}{ }^{-1} \cdot \mathrm{h}^{-1}\right)\end{array}$ \\
\hline HT-act & 161 & 134 & 0.46 & 220 \\
\hline HT/CNF-act & 750 & 542 & 0.40 & 547 \\
\hline
\end{tabular}


Technology Foundation (CW/STW 790.35.733) is acknowledged for financial support.

\section{Notes and references}

$\dagger$ Carbon nanofibers were grown from $\mathrm{CH}_{4}$ over a pre-shaped $\mathrm{Ni} / \mathrm{SiO}_{2}$ catalyst at $843 \mathrm{~K}$. Removal of the growth catalyst and oxidation of CNF was performed as reported in the literature. ${ }^{20,21} \mathrm{Mg}-\mathrm{Al}$ hydrotalcite was deposited on CNF by incipient wetness impregnation of an aqueous solution of $\mathrm{Mg}\left(\mathrm{NO}_{3}\right)_{2}(1.4 \mathrm{M})$ and $\mathrm{Al}\left(\mathrm{NO}_{3}\right)_{3}(0.7 \mathrm{M})$ and after drying at $393 \mathrm{~K}$ followed by impregnation of a solution containing $\mathrm{NaOH}(8.3 \mathrm{M})$ and $\mathrm{Na}_{2} \mathrm{CO}_{3}(0.56 \mathrm{M})$. After aging for $24 \mathrm{~h}$ at $333 \mathrm{~K}$, the material was thoroughly washed and dried at $393 \mathrm{~K}$. Activation of the hydrotalcite materials was performed by heat treatment at $773 \mathrm{~K}$ in $\mathrm{N}_{2}$ flow and rehydration at $293 \mathrm{~K}$ with a water-saturated $\mathrm{N}_{2}$ flow for $72 \mathrm{~h}$. The condensation of acetone $(1.8 \mathrm{~mol})$ at $273 \mathrm{~K}$ with $1 \mathrm{~g}$ of catalyst was analyzed by taking samples over time and analysed with gas chromatography. Iso-octane was used as an internal standard to calculate the amount of diacetone alcohol. Citral $(13 \mathrm{mmol})$ with acetone $(1.7 \mathrm{~mol})$ condensation was performed at $333 \mathrm{~K}$ with tetradecane as internal standard. Blank experiments showed that the CNF support does not exhibit any catalytic activity.

1 B. Choudary, M. L. Kantam, C. R. V. Reddy, K. K. Rao and F. Figueras, J. Mol. Catal. A., 1999, 146, 279.

2 A. Guida, L. M. Hassane, D. Tichit, F. Figueras and P. Geneste, Appl. Catal. A., 1997, 164, 251.

3 J. C. A. A. Roelofs, A. J. van Dillen and K. P. de Jong, Catal. Lett., 2001, 74, 91.
4 M. K. Kantam, B. M. Choudary, C. V. Reddy, K. K. Rao and F. Figueras, Chem. Commun., 1998, 9, 1033.

5 K. K. Rao, M. Gravelle, J. Sanchez-Valente and F. Figueras, J. Catal., 1998, 173, 115

6 M. J. Climent, A. Corma, S. Iborra and A. Velty, J. Catal., 2004, 221, 474.

7 D. Tichit, M. N. Benanni, F. Figueras, R. Tessier and J. Kervennal, Appl. Clay Sci., 1998, 13, 401

8 J. C. A. A. Roelofs, A. J. van Dillen and K. P. de Jong, Catal. Today, 2000, 60, 297.

9 J. C. A. A. Roelofs, D. J. Lensveld, A. J. van Dillen and K. P. de Jong, J. Catal., 2001, 203, 184

10 F. Winter, A. J. van Dillen and K. P. de Jong, J. Mol. Catal. A., 2004, 219, 273.

11 F. Cavani, F. Trifiro and A. Vaccari, Catal. Today, 1991, 11, 173.

12 F. Prinetto, D. Tichit, R. Teissier and B. Coq, Catal. Today, 2000, 55, 103.

13 D. Tichit and B. Coq, Cattech, 2004, 7, 206.

14 S. Abelló, F. Medina, D. Tichit, J. Pérez-Ramírez, J. C. Groen, J. E. Sueiras, P. Salagre and Y. Cesteros, Chem. Eur. J., 2005, 11, 728.

15 S. Abelló, F. Medina, D. Tichit, J. Pérez-Ramírez, Y. Cesteros, P. Salagre and J. E. Sueiras, Chem. Commun., 2005, 11, 1453.

16 W. T. Reichle, Solid State Ionics, 1986, 22, 135.

17 K. P. de Jong and J. W. Geus, Catal. Rev. -Sci. Eng., 2000, 42, 481.

18 S. Miyata and T. Kumura, Chem. Lett., 1973, 843.

19 M. J. Climent, A. Corma, S. Iborra, K. Epping and A. Velty, J. Catal., 2004, 225, 316

20 M. L. Toebes, J. M. P. van Heeswijk, J. H. Bitter, A. J. van Dillen and K. P. de Jong, Carbon, 2004, 42, 307.

21 F. Winter, G. L. Bezemer, C. van der Spek, J. D. Meeldijk, A. J. van Dillen, J. W. Geus and K. P. de Jong, Carbon, 2005, 43, 327. 